\title{
PENENTUAN KESESUAIAN LOKASI MARIKULTUR IKAN KERAPU DI SUMATERA UTARA, INDONESIA MENGGUNAKAN GOOGLE EARTH ENGINE
}

\author{
Seftiawan Samsu Rijal ${ }^{a, *}$, Gerardus David Ady Purnama Bayuaji ${ }^{\mathrm{a}}$
}

${ }^{a} I l m u$ Kelautan, Fakultas Perikanan dan Ilmu Kelautan Universitas Brawijaya, Malang, Indonesia

*Koresponden penulis: seftiawan.sr@ub.ac.id

\begin{abstract}
Abstrak
Provinsi Sumatera Utara di Indonesia tercatat telah memproduksi komoditas ekspor yang sangat tinggi untuk Ikan Kerapu. Hal ini harus dipertahankan sebagai upaya menjaga keberlangsungan ekonomi perikanan. Salah satu cara mengembangbiakan Ikan Kerapu adalah dengan marin akuakultur (marikultur) yang sangat bergantung pada ekologi lautan seperti keberadaan klorofil-a, Suhu Permukaan Laut (SPL), Muatan Padat Tersuspensi (MPT) dan topografi kedalaman laut (batimetri). Kondisi ekologi lautan yang sangat mudah berubah menghendaki pemantauan secara berkala. Penelitian ini memiliki tujuan pertama yaitu mengetahui kemampuan data penginderaan jauh untuk mengekstraksi parameter - parameter yang digunakan untuk kelayakan lokasi marikultur Ikan Kerapu. Citra Landsat 8 digunakan untuk mengetahui klorofil-a, SPL dan MPT, sedangkan data batimetri didapatkan dari ETOPO1, sebuah data topografi skala global yang memiliki perekaman permukaan lahan (terrain) hingga dasar lautan. Tujuan yang kedua adalah mengetahui keakuratan kesesuaian lokasi marikultur yang dihasilkan oleh pemrosesan citra pada Google Earth Engine (GEE). Hasil penelitian dibandingkan dengan peta referensi mengenai lokasi marikultur yang diperoleh dari Lembaga Penerbangan dan Antariksa Nasional (LAPAN) dan menampilkan hasil pengujian matriks akurasi sebesar $80 \%$. Hal ini membuktikan data penginderaan jauh dapat digunakan untuk membantu menentukan lokasi marikultur Ikan Kerapu dan GEE adalah platform yang sesuai untuk pemantauan secara berkala dengan kemampuan olah citra melalui komputasi awan (cloud computing) sekaligus dapat melakukan analisis penjenjangan bertingkat.
\end{abstract}

\section{Kata kunci: Google Earth Engine, Ikan Kerapu, Marikultur}

\begin{abstract}
North Sumatera province in Indonesia produces the highest number of export commodities of grouper fish. This need to be maintained as a part of sustainable fisheries economy. One of the methods to breeding the grouper fish is marine aquaculture (mariculture) which is very dependent on marine ecology such as the existence of chlorophyll-a, Sea Surface Temperature (SST), Total Suspended Matter (TSM), and bathymetry. Since marine ecology conditions is changes periodically, the need of temporal monitoring is indispensable. In this paper, the first aim is (1) to assess the ability of remote sensing data to extract the required parameters of grouper fish mariculture site suitability. Landsat 8 used to derive chlorophyll-a, SST and TSM, while bathymetry was obtained from ETOPO1, a global relief model that integrates land topography and ocean bathymetry. Second aim is (2) Examining the accuracy of Grouper fish mariculture site suitability. The results compared to a reference map of grouper fish site suitability from Indonesian National Institute of Aeronautics and Space (LAPAN) and reach $80 \%$ of total accuracy from confusion matrix. Generally, remote sensing data is appropriate to determine site selection of grouper fish mariculture and GEE has proven to be a reliable platform to not only periodically monitoring mariculture site suitability but also able to perform cloud-based processing imagery with weighted sum method.
\end{abstract}

Keywords: Google Earth Engine, Grouper Fish, Mariculture

\section{PENDAHULUAN}

Marin akuakultur (marikultur) adalah segala macam aktivitas yang berkaitan dengan budidaya, manajemen dan pemanenan organisme laut pada lingkungan asli tempat organisme tersebut hidup [1]. Marikultur berperan besar terhadap devisa Indonesia sebab sebagian besar produknya diekspor ke luar negeri [2]. Berdasarkan data yang dirilis oleh Food and Agriculture Organization (FAO) pada tahun 2020, Indonesia adalah negara ke-3 
terbesar dunia penghasil ikan bersirip (finfish) yang berasal dari hasil budidaya pesisir dan laut dengan jumlah produksi sepanjang 2003 2018 sebanyak 9 juta ton [3].

Salah satu komoditas ikan bersirip hasil marikultur yang paling dominan dari Indonesia adalah Ikan Kerapu. Bahkan, sekitar 26,5\% Ikan Kerapu yang ada di dunia berasal dari Indonesia [4]. Ikan Kerapu memiliki nilai ekonomi yang sangat tinggi, terlihat dari jangka waktu balik modal yang sangat cepat yakni kurang dari setahun [5].

Permintaan Ikan Kerapu dari luar negeri sangat tinggi, terutama dari Hongkong dan Republik Rakyat Tiongkok (RRT), namun demikian, Ikan Kerapu juga menghadapi ancaman berupa rendahnya kapasitas produksi yang berkaitan dengan reproduksi alami, metode penangkapan ikan yang destruktif dan pengembangbiakannya [6]. Permasalahan tersebut berkenaan dengan lokasi pengembangbiakan. Hal senada diungkapkan oleh [7] bahwa pencarian lingkungan yang sesuai bagi proses kembangbiak organisme laut adalah salah satu permasalahan yang kelak akan mengancam keberlangsungan aktivitas marikultur.

Luasnya area yang akan dipilih sebagai lokasi potensial untuk marikultur Ikan Kerapu membutuhkan metode yang efektif dan efisien dalam proses penetapannya. Szuster dan Albasri [8] membutuhkan waktu selama sebulan untuk melakukan survei pada area seluas 8500 ha, sementara itu, Anggraini dkk [9] hanya memerlukan waktu tiga hari untuk mengunjungi lokasi terpilih pada area seluas 80.390 ha setelah ia menetapkan beberapa lokasi potensial tertentu melalui metode pemrosesan citra penginderaan jauh dalam pemilihan lokasi (site selection). Perbandingan yang sangat mencolok dari lama waktu survei pada kedua penelitan tersebut dimana keduanya sama - sama mencari lokasi yang paling layak untuk marikultur Ikan Kerapu.

Kehadiran citra penginderaan jauh dapat membantu menentukan beberapa kandidat lokasi marikultur dengan berbagai parameter yang dapat kita kontrol. Beberapa penelitian terdahulu telah melakukan pencarian kesesuaian lokasi marikultur menggunakan beragam data citra penginderaan jauh seperti
ALOS, NOAA AVHRR, dan Landsat 8 [9-11]. Meskipun demikian, penelitian tersebut hanya memproses citra yang diakuisisi satu waktu dan belum diproses pada platform komputasi awan layaknya Google Earth Engine (GEE). Pemrosesan citra yang hanya diakuisisi satu waktu mungkin akan kurang representatif dalam menampilkan pencarian kesesuaian lokasi marikultur sebab kondisi lingkungan laut yang sangat cepat berubah baik dalam hitungan hari ataupun minggu tergantung pada variabilitas musiman.

Berdasarkan hal tersebut diatas, penelitian ini mengajukan dua tujuan yaitu mengetahui kemampuan data penginderaan jauh untuk mengekstraksi parameter - parameter yang digunakan untuk menentukan kelayakan lokasi marikultur Ikan Kerapu menggunakan GEE dan yang kedua adalah mengetahui keakuratan kesesuaian lokasi marikultur yang dihasilkan oleh pemrosesan citra pada GEE. GEE dibekali kemampuan superkomputer dengan basis komputasi awan yang mampu mengolah citra multitemporal dengan sekali proses serta kemampuan yang lebih kompleks untuk kalkulasi citra secara masif [12].

\section{METODE}

\section{Area Penelitian}

Provinsi Sumatera Utara beribukota Medan dengan luas wilayah mencakup $772.981 \mathrm{~km}^{2}$. Provinsi Sumatera Utara merupakan penghasil Ikan Kerapu terbesar di Indonesia dengan total jumlah produksi melebihi 34 ribu ton Ikan Kerapu telah dihasilkan dalam kurun waktu 2011 - 2020 [13]. Sebagai perbandingan, Kepulauan Riau sebagai provinsi terbanyak kedua yang menghasilkan Ikan Kerapu hanya memproduksi sekitar 22 ribu ton dalam kurun waktu yang sama.

Provinsi Sumatera Utara secara konsisten memberikan sumbangan produksi Ikan Kerapu dalam kurun 10 tahun terakhir pada angka 3000 hingga 5000 ton per tahun, hanya pada tahun 2017 produksinya turun menjadi sekitar 1000 ton. Keberlangsungan produksi Ikan Kerapu di Provinsi Sumatera Utara patut dijaga 
untuk mempertahankan devisa dari ekonomi perikanan.

Penelitian penentuan lokasi kesesuaian marikultur dilakukan pada zona 12 mil laut dari pesisir Provinsi Sumatera Utara, yang ditampilkan dengan warna kuning pada Gambar 1. Jarak ini didasarkan pada wilayah laut yang dapat dikelola provinsi sesuai amanat Rencana Zonasi Wilayah Pesisir dan Pulau Pulau Kecil [23].

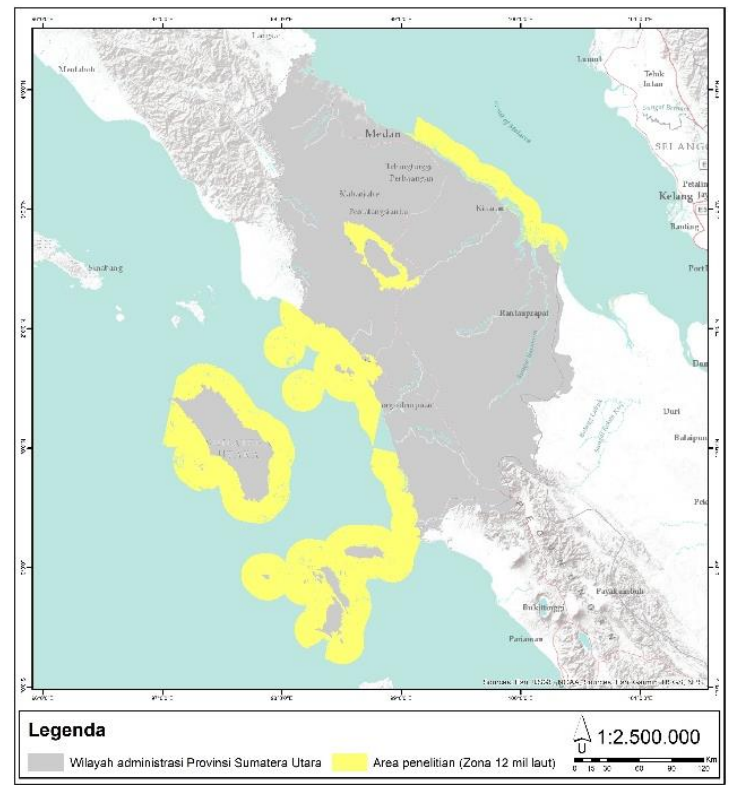

Gambar 1. Area penelitian

\section{Landsat 8}

Landsat 8 merupakan proyek lanjutan dari Landsat Data Continuity Mission (LDCM) yang diluncurkan pada tahun 2013 dengan membawa instrumen Operational Land Imager (OLI) dan Thermal Infrared Sensor (TIRS) (14). Data citra Landsat 8 yang digunakan memiliki masa waktu perekaman sepanjang tahun 2018. Hal ini dilakukan untuk menyamakan waktu pemodelan dengan peta referensi yang akan dijelaskan pada bagian pengujian akurasi.

Landsat 8 dilengkapi berbagai macam panjang gelombang untuk melakukan penginderaan, 9 panjang gelombang spektral pada instrument OLI mulai dari panjang gelombang tampak, cirrus/coastal aerosol, inframerah dan pankromatik. Sementara, pada TIRS terdapat 2 panjang gelombang yaitu
TIRS 1 dan TIRS 2. Lebih jelas mengenai spesifikasi Landsat 8 dapat dilihat pada Tabel 1 dibawah ini.

Tabel 1. Karakteristik Satelit Landsat 8

\begin{tabular}{|c|c|}
\hline Resolusi & Spesifikasi \\
\hline \begin{tabular}{ll}
\multicolumn{2}{l}{ Spasial $(\mathrm{m})$} \\
- & OLI \\
- & Pankromatik \\
- & TIRS \\
\end{tabular} & $\begin{array}{l}30 \\
15 \\
100 \\
\end{array}$ \\
\hline $\begin{array}{l}\text { Radiometrik } \\
\text { (bit) }\end{array}$ & 12 \\
\hline Temporal (hari) & 16 \\
\hline $\begin{array}{l}\text { Spektral }(\mu \mathrm{m}) \\
-\quad \text { OLI }\end{array}$ & $\begin{array}{l}\text { Band } 1 \text { Visible }(0.43 \text { - } \\
0.45) \\
\text { Band } 2 \text { Visible }(0.45 \text { - } \\
0.51) \\
\text { Band } 3 \text { Visible }(0.53 \text { - } \\
0.59) \\
\text { Band } 4 \text { Red }(0.64-0.67) \\
\text { Band } 5 \text { Near Infrared } \\
(0.85 \text { - } 0.88) \\
\text { Band } 6 \text { SWIR } 1(1.57 \text { - } \\
1.65) \\
\text { Band } 7 \text { SWIR } 2(2.11 \text { - } \\
2.29) \\
\text { Band } 9 \text { Cirrus }(1.36 \text { - } \\
1.38) \\
\text { Band } 8 \text { (0.50 - } 0.68) \\
\text { Band } 10 \text { TIRS } 1(10.6 \text { - } \\
11.19) \\
\text { Band } 11 \text { TIRS } 2(11.5 \text { - } \\
12.51)\end{array}$ \\
\hline
\end{tabular}

Sumber: [14]

Landsat 8 terlebih dahulu harus melewati tahap pra pemrosesan untuk mengubah nilai Digital Number (DN) ke reflektansi Top of Atmosphere (ToA) sebelum melakukan proses ektraksi dengan persamaan berikut [14],

$\rho \lambda^{\natural}=\mathrm{M} \rho \mathrm{Qcal}+\mathrm{A} \rho \ldots$

dimana:

$\rho \lambda^{6} \quad:$ ToA

M $\rho$ : Faktor penskalaan ulang pengali spesifik per band (berasal dari metadata citra)

A $\rho \quad$ : Faktor penskalaan ulang penambah spesifik per band (berasal dari metadata citra)

Qcal : Nilai DN 
Setelah nilai piksel Landsat 8 berhasil diubah menjadi nilai reflektansi ToA, maka diterapkan rumus ekstraksi masing - masing parameter. Berikut rumus ekstraksi klorofil-a [15]:

$0,2818 x\left(\frac{\text { Band Merah }}{\text { Band NIR+Band SWIR }}\right)^{3,497}$

rumus ekstraksi SPL menggunakan algoritma Split Window (16):

$(($ Band $10-273)+(2.946 \times(($ Band $10-273)$

- (Band $11-273)))-0,038) \ldots$ (3)

dan rumus ekstraksi MPT (17):

$8,1429^{(23,704} \times$ Band Merah)

\section{ETOPO1}

Penelitian ini mengajukan penggunaan data ETOPO1 untuk mengekstrak informasi batimetri. ETOPO1 adalah data Digital Elevation Model (DEM) yang memiliki cakupan global. Sedikit berbeda dengan data DEM global lainnya seperti SRTM dan ALOS GDEM, yang hanya memiliki data ketinggian daratan dan tidak memiliki data kedalaman laut, ETOPO1 telah mengintegrasikan data daratan serta kedalaman laut dalam perekamannya, sehingga selain ketinggian daratan, relief dasar laut pun dapat diidentifikasi oleh data ini [18].

ETOPO1 juga memiliki resolusi piksel sebesar 1 arc-minute. Nilai ini setara dengan resolusi spasial berukuran $30 \mathrm{~m}$ yang merupakan resolusi spasial dari landsat 8 . Kesamaan resolusi spasial dari kedua data diharapkan dapat semakin membuat hasil yang dicapai lebih representatif.

\section{Analisis Berjenjang Tertimbang Pada Google Earth Engine}

Google Earth Engine (GEE) adalah platform yang dapat digunakan untuk melakukan pemrosesan data spasial berbasis komputasi awan [19]. Selain pemrosesan, GEE juga merupakan tempat penyimpanan berbagai data spasial dengan umur data sejak 1970-an seperti Landsat 1 hingga data terkini yang bebas akses. Apabila analisis yang akan dilakukan cukup dengan menggunakan data yang tersedia di GEE, pengguna dapat langsung memprosesnya tanpa harus mengunggahnya terlebih dahulu. Namun demikian, menu unggah dan unduh data pada GEE juga tersedia untuk memudahkan pengguna mengolah data pribadinya sendiri. GEE berjalan dengan bahasa pemrograman JavaScript atau phyton [20]. Perintah untuk pemrosesan citra pada penelitian ini dilakukan dengan JavaScript.

Contoh perintah yang digunakan antara lain filterDate(), clip(), Map.setCenter(), \| (or), $\& \&$ (and), A?B:C (if, then, else), multiply(), $a d d()$ dan lainnya. Agar dapat memproses citra pada GEE, pengguna perlu mendaftar di https://earthengine.google.com/ dan kemudian masuk ke dalam tautan berikut https://code.earthengine.google.com/ untuk menuliskan perintah yang ingin dieksekusi.

Analisis berjenjang tertimbang (weighted sum) adalah metode pemberian harkat dan bobot pada masing - masing parameter yang digunakan dalam penelitian. Hal ini didasari oleh pertimbangan bahwa tidak semua kondisi pada parameter yang digunakan memiliki kontribusi yang sama pada objek yang dikaji. Pengharkatan setiap parameter yang digunakan pada penelitian ini yaitu klorofil-a, SPL, MPT dan batimetri mengacu pada penelitian yang dilakukan oleh [21] dengan rincian seperti pada Tabel 2. Terdapat 3 harkat yang digunakan yaitu 5, 3 dan 1. Pemberian harkat dilakukan pada sebuah rentang nilai yang ada pada setiap parameter. Semakin tinggi harkat maka semakin sesuai rentang nilai pada setiap parameter tersebut untuk kesesuaian lokasi marikultur Ikan Kerapu.

Hasil pengharkatan pada setiap parameter perlu dibobotkan agar diperoleh hasil akhir yang sesuai dengan kondisi alami. Pembobotan adalah faktor pengali untuk setiap rentang nilai pada masing - masing parameter yang telah memiliki harkat. Berikut bobot untuk setiap parameter yang mengacu pada penelitian [21] (Tabel 3). Terdapat 3 macam bobot atau faktor pengali yang digunakan yaitu 1 untuk klorofila, 2 untuk SPL dan 3 untuk MPT dan batimetri. 
Tabel 2. Pengharkatan setiap paramater

\begin{tabular}{lccc}
\hline Parameter & $\mathbf{3}$ & $\mathbf{3}$ & $\mathbf{1}$ \\
\cline { 2 - 4 } $\begin{array}{l}\text { Klorofil-a } \\
\left(\mathrm{mg} / \mathrm{m}^{3}\right)\end{array}$ & $>10$ & $4-10$ & $<4$ \\
SPL $\left({ }^{\circ} \mathrm{c}\right)$ & $28-30$ & $\begin{array}{c}25-27 \text { dan } \\
31-32\end{array}$ & $\begin{array}{c}<25 \\
\text { dan }> \\
32\end{array}$ \\
$\begin{array}{l}\text { MPT } \\
(\mathrm{mg} / \mathrm{l})\end{array}$ & $<25$ & $25-50$ & $>50$ \\
$\begin{array}{l}\text { Batimetri } \\
(\mathrm{m})\end{array}$ & $15-25$ & $\begin{array}{c}5-15 \text { atau } \\
26-35\end{array}$ & $\begin{array}{c}<5 \\
\text { atau } \\
35\end{array}$ \\
\hline
\end{tabular}

Tabel 3. Pembobotan setiap parameter

\begin{tabular}{lc}
\hline Parameter & Bobot \\
\hline Klorofil-a $\left(\mathrm{mg} / \mathrm{m}^{3}\right)$ & 1 \\
SPL $\left({ }^{\circ} \mathrm{c}\right)$ & 2 \\
MPT $(\mathrm{mg} / \mathrm{l})$ & 3 \\
Batimetri $(\mathrm{m})$ & 3 \\
\hline
\end{tabular}

Pembobotan setiap paramater akan menghasilkan nilai tertentu. Pengelompokkan rentang nilai hasil pembobotan tersebut perlu dilakukan agar setiap rentang nilai kelas dapat diklasifikasi menjadi wilayah yang sangat sesuai, sesuai, cukup sesuai atau tidak sesuai untuk lokasi marikultur Ikan Kerapu. Tabel 4 dibawah ini menunjukkan rentang nilai kelas dan kesesuaiannya untuk menjadi lokasi marikultur Ikan Kerapu.

Tabel 4. Klasifikasi rentang nilai

\begin{tabular}{lc}
\hline Kelas & Rentang Nilai \\
\hline Sangat Sesuai & $33.76-45$ \\
Sesuai & $22.6-33.75$ \\
Cukup Sesuai & $11.26-22.5$ \\
Tidak Sesuai & $0-11.25$ \\
\hline
\end{tabular}

\section{Pengujian Akurasi}

Akurasi hasil pemetaan pada penelitian ini dibandingkan dengan peta referensi lokasi kesesuaian budidaya Ikan Kerapu di Sumatera Utara yang diterbitkan oleh Lembaga Penerbangan dan Antariksa Nasional (LAPAN) yang dapat diakses melalui https://spbn.pusfatja.lapan.go.id/layers/geonod e\%3Akr_sumut.
Perbandingan uji akurasi dilakukan menggunakan confusion matrix yang dapat membandingkan peta hasil dengan peta referensi secara kuantitatif melalui perhitungan akurasi keseluruhan (Overall Accuracy). Akurasi keseluruhan didapatkan dengan cara membagi hasil penjumlahan titik pengamatan yang benar pada garis diagonal yang terdapat pada matriks konfusi dengan jumlah keseluruhan titik pengamatan [22]. Selain Overall Accuracy (OA), confusion matrix juga dapat menghasilkan User Accuracy (UA) yang menggambarkan sebaik apa hasil klasifikasi merepresentasikan kondisi nyata di lapangan dan Producer Accuracy (PA) yang menggambarkan sebaik apa sebuah piksel terklasifikasikan.

Strategi pengambilan sampel uji akurasi dilakukan dengan metode sampel acak setara (equal random sampling). Setiap kelas kesesuaian memiliki jumlah sampel yang sama namun peletakannya dilakukan secara acak. Total terdapat 120 sampel untuk tiga kelas kesesuaian.

\section{Alur Penelitian}

Penelitian dimulai dengan menetapkan lokasi penelitian dan memilih data citra yang dapat digunakan. Penelitian ini menggunakan Landsat 8 karena mampu mengekstrak parameter penentu lokasi marikultur Ikan Kerapu seperti klorofil-a, SPL, dan MPT [9]. Sedangkan untuk data batimetri, penelitian ini menggunakan data ETOPO1 yang belum pernah digunakan pada beberapa penelitian sebelumnya. ETOPO1 dipilih karena tersedia secara gratis, memiliki cakupan global baik relief dataran maupun relief dasar laut.

Landsat 8 disiapkan dengan koreksi radiometrik terlebih dahulu untuk mengubah nilai Digital Number (DN) menjadi nilai reflektansi Top of Atmosphere (ToA). Kemudian Landsat 8 yang telah bernilai reflektansi ToA tersebut diekstrak untuk menghasilkan nilai klorofil-a, SPL dan MPT. Adapun ETOPO1 dapat langsung digunakan untuk identifikasi nilai kedalaman perairan karena merupakan data siap pakai.

Nilai klorofil-a, SPL dan MPT dari Landsat 8 selanjutnya dikelaskan dengan analisis 
berjenjang tertimbang berdasarkan harkat dan bobot tertentu. Kelas yang digunakan ada empat yaitu Sangat Sesuai, Sesuai, Cukup Sesuai dan Tidak Sesuai. Hasil pengkelasan tersebut kemudian diuji akurasinya dengan cara dibandingkan dengan peta referensi dari LAPAN menggunakan confusion matrix. Hal ini dilakukan untuk melihat ketepatan model yang telah dibuat dengan kondisi lapangan yang sesungguhnya. Seluruh proses pengolahan citra dilakukan pada platform komputasi awan yaitu GEE. Agar lebih jelas mengenai alur penelitian dapat melihat Gambar 2 dibawah ini.

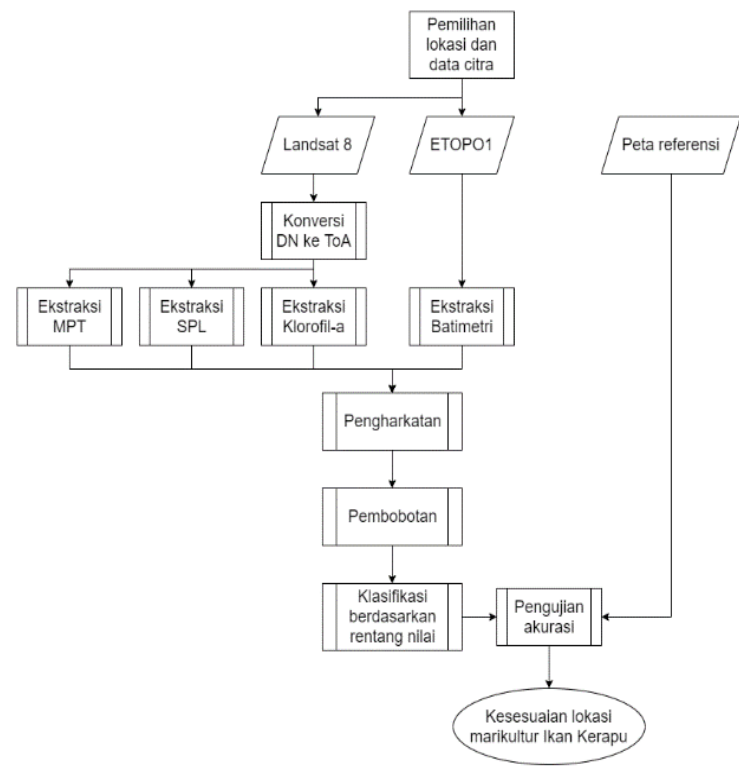

Gambar 2. Alur penelitian

\section{HASIL DAN PEMBAHASAN}

GEE memiliki kemampuan untuk
menampilkan dan $\begin{array}{r}\text { mengolah citra } \\ \text { multitemporal dalam satu kali pemrosesan }\end{array}$
sekaligus. Meskipun demikian, tetap ada
mekanisme kontrol yang dilakukan agar
pemrosesan citra oleh GEE terarah dan sesuai
dengan tujuan penelitian. Pengontrolan
pemrosesan citra Landsat 8 pada GEE di
penelitian ini dilakukan dengan beberapa
perintah seperti.filterDate, filterMetadata
dan .Mean. Artinya, citra Landsat 8 yang
tersedia sepanjang tahun 2018 tidak semuanya
diolah. Pemilihan dilakukan berdasarkan
rentang tanggal (1 Januari - 31 Desember

2018), dan hanya memproses citra dengan tutupan awan kurang dari $10 \%$ serta hanya citra yang memiliki nilai piksel yang secara statistik termasuk dalam rentang pertengahan (mean). Penentuan ini dilakukan untuk mencari citra dengan kondisi terbaik yaitu tutupan awan kurang dari $10 \%$ pada seluruh scene.

Adapun untuk data batimetri, pemilihan data tidak dilakukan berdasarkan rentang tanggal perekaman. Hal ini dikarenakan ETOPO1 tidak merekam secara berkala dan hanya sekali merekam. Kontrol terhadap ETOPO1 yang diproses pada GEE hanya dilakukan pada pemilihan jenis data yaitu data bedrock yang merepresentasikan kedalaman perairan.

Pemrosesan data citra Landsat 8 maupun ETOPO1 dilakukan pada wilayah perairan. Proses ekstraksi parameter dari kedua data tersebut juga dilakukan pada seluruh liputan citra (scene) bukan pada stasiun pengamatan tertentu yang ada di lapangan. Code yang diterapkan dalam pengolahan citra ini merupakan modifikasi dari [24] dapat dilihat melalui tautan berikut: https://code.earthengine.google.com/a755707 1ee2bd4f1054c8fac6c7f 4897

\section{Ekstraksi Parameter}

Hasil ekstraksi Landsat 8 untuk klorofil-a menunjukkan rentang nilai $0,0000114 \mathrm{mg} / \mathrm{l}$ hingga $361,38 \mathrm{mg} / \mathrm{l}$. Rata - rata nilai klorofil-a adalah $0,714 \mathrm{mg} / \mathrm{l}$. Nilai klorofil-a berkenaan dengan jumlah dan kepadatan fitoplankton pada suatu perairan. Meskipun klorofil-a tidak secara langsung berhubungan dengan organisme budidaya, namun demikian klorofila dapat menjadi penanda keseimbangan atau kesuburan perairan [21].

Nilai rerata SPL yang berhasil diekstrak Landsat 8 pada penelitian ini adalah $30,99{ }^{\circ} \mathrm{C}$. SPL adalah salah satu faktor yang penting baik dalam penentuan kesesuaian lokasi budidaya maupun oceanografi pada umumnya [25].

Nilai MPT memiliki rata - rata $460(\mathrm{mg} / \mathrm{l})$ dengan nilai minimail $1.602(\mathrm{mg} / \mathrm{l})$ dan nilai maksimal $2.283 \quad(\mathrm{mg} / \mathrm{l})$. MPT Bersama klorofil-a dapat menentukan kesuburan perairan [26]. 
Tabel 5. Nilai hasil ekstraksi setiap paramater

\begin{tabular}{lrrrr}
\hline Parameter & Klorofil-a $\left(\mathbf{m g} / \mathbf{m}^{\mathbf{3}}\right)$ & SPL $\left({ }^{\circ} \mathbf{C}\right)$ & MPT $(\mathbf{m g} / \mathbf{l})$ & Batimetri $(\mathbf{m})$ \\
\hline Nilai Minimal & 0.0000114 & -89.81 & 1.602 & -1633 \\
\hline Nilai Maksimal & 361.38 & 86.22 & 2.283 & 1457 \\
\hline Nilai Rata - rata & 0.714 & 30.99 & 460 & -108.90 \\
\hline
\end{tabular}

Kedalaman perairan (batimetri) yang dapat diidentifikasi berkisar pada rentang $-1633 \mathrm{~m}$ (nilai terendah) dan $1457 \mathrm{~m}$ (nilai tertinggi), rerata kedalaman perairan adalah $-108,90 \mathrm{~m}$. Kedalaman perairan dalam budidaya organisme perairan menentukan jumlah dan jenis organisme yang dapat mendiaminya, penetrasi cahaya, penyebaran plankton dan penentuan instalasi budidaya yang akan dilakukan (21). Agar lebih jelas mengenai hasil identifikasi rentang nilai maksimal, minimal dan rata - rata untuk setiap parameter dapat melihat Tabel 5.

\section{Kesesuaian Lokasi Marikultur}

Analisis kesesuaian lokasi marikultur Ikan Kerapu didasarkan pada parameter, rentang nilai dan faktor pengali yang terdapat pada Tabel 2, Tabel 3, dan Tabel 4. Pada Tabel 2 berisi rentang nilai dari setiap parameter yang akan diberi harkat, sedangkan pada Tabel 3 rentang nilai yang telah memiliki harkat tersebut akan dikalilkan dengan faktor pengali dari suatu bobot. Hasil akhir dari semua perhitungan tersebut kemudian dikelaskan menjadi beberapa kelas yaitu Sangat Sesuai, Sesuai, Cukup Sesuai dan Tidak Sesuai.

Rentang nilai minimum, maksimum, dan nilai rata rata dari setiap parameter yang berhasil diekstrak dari data citra Landsat 8 dan ETOPO1 menunjukkan nilai yang tidak memenuhi kriteria standar kesesuaian lokasi marikultur Ikan Kerapu sebagaimana yang terdapat pada Tabel 2. Namun demikian, hasil akhir dari pembobotan setiap parameter dan klasifikasi rentang nilai masih menunjukkan terdapatnya lokasi - lokasi yang memenuhi persyaratan untuk aktivitas marikultur Ikan Kerapu seperti yang ditunjukkan oleh Gambar 3.

Berbeda dengan beberapa penelitian sebelumnya yang telah dilakukan oleh
$(15,21,26)$ dimana pada penelitian tersebut ditentukan beberapa stasiun lapangan untuk pengambilan data lapangan dari setiap parameter, penelitian ini sepenuhnya memperoleh data setiap parameter tersebut hanya dari citra. Tidak terdapat stasiun lapangan pada penelitian ini.

Rentang nilai minimum, maksimum dan rata - rata yang dihasilkan pun merupakan hasil olah citra dari seluruh liputan citra (scene) pada wilayah perairan Provinsi Sumatera Utara yang dibatasi hingga 12 mil laut. Sehingga, nilai yang ditampilkan adalah kondisi keseluruhan wilayah yang diamati, bukan pada titik - titik tertentu layaknya penempatan sebuah stasiun pengamatan. Namun demikian, apabila dilakukan pengecekan secara acak ke setiap lokasi kelas kesesuaian, hal tersebut masih tercakup dalam kriteria kesesuaian yang terdapat pada Tabel 2 sebagaimana yang tampak pada titik putih di Inzet dari Gambar 3. Pada titik putih tersebut diketahui bahwa klorofil-a bernilai $0,20 \mathrm{mg} / \mathrm{m}^{3}$, SPL $28,83{ }^{\circ} \mathrm{C}$, MPT 7,55 mg/l dan kedalaman perairan (batimetri) sedalam $21 \mathrm{~m}$. Nilai SPL, MPT dan batimetri termasuk dalam harkat 5 sedangkan klorofil-a termasuk pada harkat 1 pada Tabel 2 . Sebanyak 3 dari 4 parameter memiliki harkat 5 , hal ini menandakan lokasi ini sangat sesuai untuk dijadikan lokasi marikultur Ikan Kerapu

\section{Hasil Uji Akurasi}

Uji akurasi terdiri atas 3 pengecekan, yaitu User accuracy (UA), Producer Accuracy (PA), Overall Accuracy (OA). Penilaian PA dan UA dilakukan pada setiap kelas sedangkan OA merupakan hasil perbandingan keseluruhan kelas.

UA adalah hasil bagi antara total kolom setiap kelas dengan jumlah titik yang benar pada kolom tersebut sedangkan PA adalah hasil bagi antara total baris setiap kelas dengan 
Tabel 6. Hasil uji akurasi

\begin{tabular}{|c|c|c|c|c|c|}
\hline Klasifikasi & $\begin{array}{l}\text { Cukup } \\
\text { Sesuai }\end{array}$ & Sesuai & $\begin{array}{l}\text { Sangat } \\
\text { Sesuai }\end{array}$ & $\begin{array}{l}\text { Total } \\
\text { Baris }\end{array}$ & $\begin{array}{l}\text { User Accuracy } \\
\text { (UA) }\end{array}$ \\
\hline Cukup Sesuai & 31 & 1 & 2 & 34 & $91 \%$ \\
\hline Sesuai & 9 & 35 & 5 & 49 & $71 \%$ \\
\hline Sangat Sesuai & 2 & 4 & 31 & 37 & $84 \%$ \\
\hline Total Kolom & 42 & 40 & 38 & 96 & \\
\hline Producer Accuracy (PA) & $74 \%$ & $88 \%$ & $82 \%$ & & \\
\hline Overall Accuracy (OA) & $80 \%$ & & & & \\
\hline Total Jumlah Sampel & 120 & & & & \\
\hline
\end{tabular}

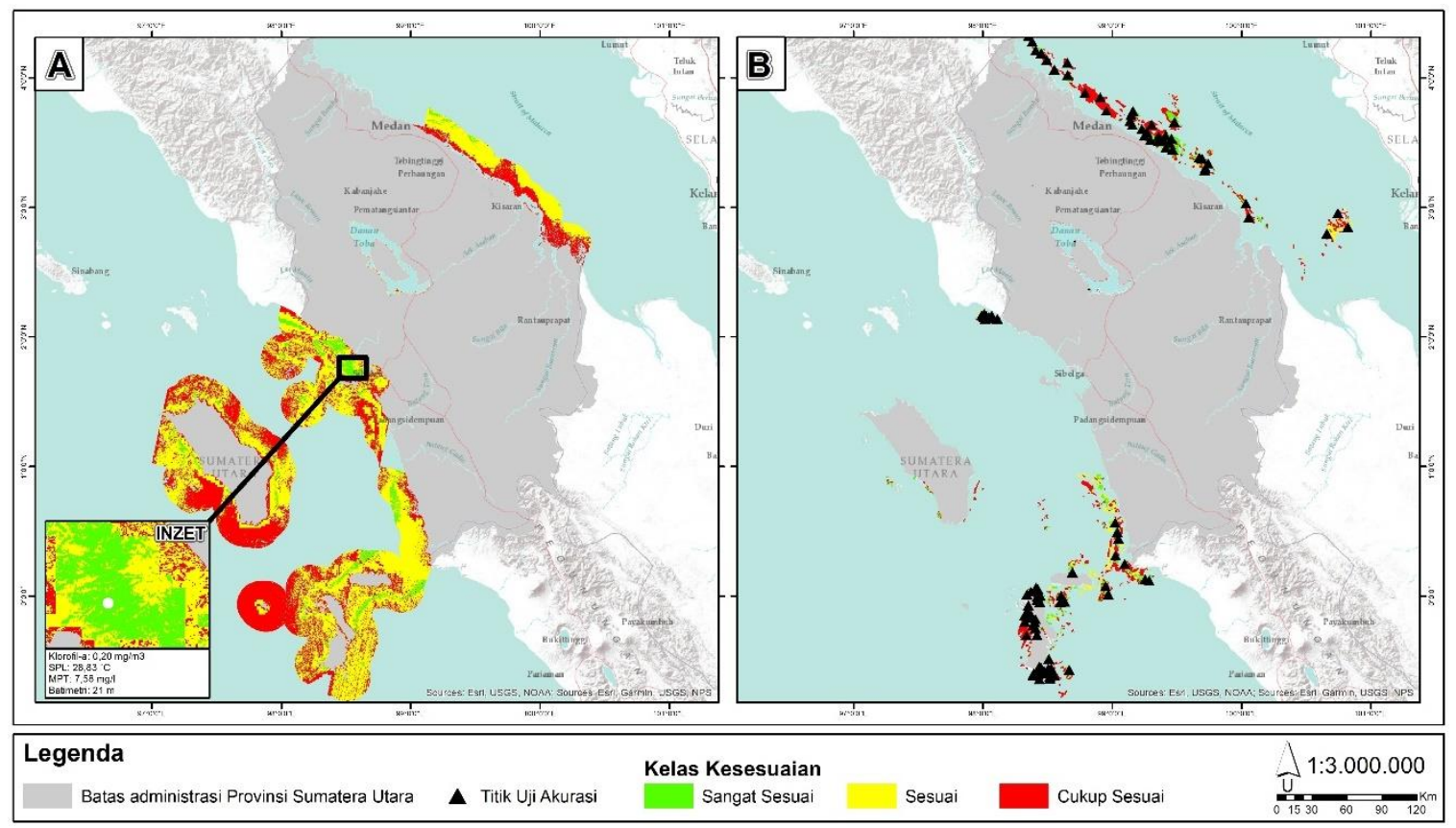

Gambar 3. Kelas kesesuaian lokasi marikultur Ikan Kerapu di Provinsi Sumatera Utara hasil pemodelan menggunakan GEE (A) dan peta referensi dari LAPAN (B)

jumlah titik yang benar. Titik yang benar diberi warna abu - abu pada setiap kelas. Sementara OA dihitung dari jumlah total baris dan total kolom kemudian dibagi dengan total seluruh jumlah titik uji dan dikalikan 100\%. Agar lebih jelas mengenai tabel uji akurasi menggunakan confusion matrix dapat melihat Tabel 6.

Pada kelas Sangat Sesuai nilai UA adalah $84 \%$ sedangkan nilai PA adalah $82 \%$. Pada kelas Sesuai nilai UA adalah $71 \%$ sedangkan nilai PA adalah $88 \%$. Pada kelas Cukup Sesuai nilai UA adalah $91 \%$ sedangkan nilai PA adalah $74 \%$. Apabila nilai UA lebih besar daripada nilai PA maka dinyatakan underestimated sedangkan apabila nilai PA lebih besar daripada nilai UA maka dinyatakan overestimated [22]. Berdasarkan hal ini, dapat dinyatakan bahwa kelas Sangat Sesuai dan Cukup Sesuai berada pada kondisi underestimated sedangkan kelas Sesuai berada pada kondisi overestimated. Adapun nilai OA adalah senilai $80 \%$. Menurut [27] target akurasi pemetaan tematik menggunakan data penginderaan jauh untuk berbagai tujuan berkisar pada angka 85\%, dengan demikian nilai OA yang dicapai pada penelitian ini sudah hampir mencapai target akurasi pemetaan yang umumnya dilakukan menggunakan data penginderaan jauh. Selain itu, hal ini juga mengonfirmasi bahwa kriteria, rentang nilai, 
harkat dan bobot dari beragam parameter kesesuaian yang diekstrak dari data penginderaan jauh sebagaimana yang terdapat pada Tabel 2, Tabel 3 dan Tabel 4 cukup layak digunakan dalam penentuan lokasi marikultur Ikan Kerapu.

Perhitungan luasan area setiap kelas kesesuaian dilakukan untuk mengetahui seberapa besar lokasi potensial yang dapat dijadikan tempat marikultur Ikan Kerapu. Tabel 7 memperlihatkan bahwa dari hasil pengolahan GEE kelas dengan luasan terbesar adalah kelas Sesuai dengan 16.991,48 Ha.

Tabel 7. Perbandingan luas setiap kelas

\begin{tabular}{lcr}
\hline Kelas & $\begin{array}{l}\text { Hasil GEE } \\
\text { (Ha) }\end{array}$ & $\begin{array}{l}\text { Peta Referensi } \\
\text { (Ha) }\end{array}$ \\
\hline Cukup Sesuai & $11.670,31$ & $3.401,17$ \\
\hline Sesuai & $16.991,48$ & $5.471,80$ \\
\hline Sangat Sesuai & $1.597,15$ & $1.145,01$ \\
\hline Total & $30.258,94$ & $10.323,07$ \\
\hline
\end{tabular}

Adapun kelas yang memiliki luasan terkecil adalah kelas Sangat Sesuai yakni hanya $1.579,15$ Ha. Total keseluruhan luasan area yang diolah pada GEE mencapai 30.258,94 Ha. Apabila dibandingkan dengan peta referensi, baik luasan per kelas atau total luasan terlihat sangat jauh perbedaannya. Hal ini dikarenakan peta referensi tidak menentukan lokasi potensial marikultur Ikan Kerapu berdasarkan batas 12 mil sesuai ketentuan RZWP3K.

Berdasarkan hal ini, model yang dibangun dapat dijadikan salah satu alternatif data tambahan untuk semakin memperkaya informasi lokasi potensial marikultur Ikan Kerapu namun dengan tetap berupaya untuk meningkatkan akurasi hasil pemodelan. Semakin akurat model maka akan semakin memudahkan pengguna untuk mengambil kebijakan berbasis pemodelan spasial.

\section{KESIMPULAN}

Citra penginderaan jauh memiliki kemampuan untuk mengekstrak beberapa parameter penentu lokasi potensial untuk marikultur Ikan Kerapu dengan pendekatan synoptic overview atau cakupan umum sebuah kondisi dari suatu wilayah. Hal ini diperlukan untuk melihat gambaran awal wilayah kajian. Pendalaman khusus pada area tertentu sebagai basis pengambilan sampel atau pengujian akurasi tetap harus dilakukan agar hasil pengolahan citra terkonfirmasi kebenarannya. Penelitian ini sepenuhnya melakukan pengolahan citra tanpa pengambilan sampel seperti pembuatan stasiun di lapangan. Akhirnya, hasil ekstraksi parameter yang didapatkan dari hasil olah citra pada satu scene bukan pada titik - titik pengamatan tertentu memiliki rentang yang sangat besar dan bervariasi.

Penelitian selanjutnya lebih baik jika dilakukan dengan pembuatan stasiun setelah pengolahan citra untuk mengonfirmasi hasil olah citra atau pengecekan kebenaran hasil olah citra/uji akurasi juga dapat dilakukan dengan mendatangi langsung beberapa area yang telah memiliki kegiatan marikultur Ikan Kerapu sebelumnya.

Kemampuan GEE dalam mengolah citra multitemporal dapat dijadikan pertimbangan untuk digunakan pada penelitian selanjutnya. Nilai hasil pengujian akurasi sebesar $80 \%$ merupakan bukti bahwa GEE memiliki kemampuan analisis berjenjang bertingkat (weighted sum) cukup baik yang dapat dilakukan dengan komputasi awan (cloud computing).

\section{UCAPAN TERIMA KASIH}

Penulis mengucapkan terima kasih terhadap berbagai pihak yang telah membantu penelitian yang dikerjakan secara mandiri ini, terutama kepada komunitas GEE yang selalu berbagi pakai data script pengolahan, kemudian kepada editor dan reviewer yang telah memberi saran dan masukan yang membangun demi semakin baiknya tulisan ini.

\section{DAFTAR PUSTAKA}

[1] Laird LM. Mariculture Overview. In: Steele JHBT-E of OS, editor. Oxford: Academic Press; 2001. p. 1572-7. Available from: https://www.sciencedirect.com/science /article/pii/B012227430X004748

[2] Rimmer MA. Mariculture 
Development in Indonesia: Prospects and Constraints. Indones Aquac J. 2010;5(2):187-201.

[3] FAO. The State of World Fisheries and Aquaculture 2020. Sustainability in action. Fao. 2020. 224 p.

[4] Amorim P, Westmeyer M. Snapper and Grouper: SFP Fisheries Sustainbility Overview. Sustain Fish Partnersh Found [Internet]. 2015;18. Available from: www.fishsource.com

[5] Afero F, Miao S, Perez AA. Economic analysis of tiger grouper Epinephelus fuscoguttatus and humpback grouper Cromileptes altivelis commercial cage culture in Indonesia. Aquac Int [Internet]. 2010;18(5):725-39. Available from: https://doi.org/10.1007/s10499-0099295-x

[6] Cohcrane, K. L., Garcia SM. A Fishery Manager's Guidebook. 2nd ed. Singapore: Wiley-Blackwell and FAO; 2009. 544 p.

[7] Kapetsky JM, Aguilar-Manjarrez J, Jenness J. A global assessment of offshore mariculture potential from a spatial perspective. FAO Fisheries and Aquaculture Technical Paper. 2013. $181 \mathrm{p}$.

[8] Szuster WB, Albasri H. Site selection for grouper mariculture in Indonesia. Int $\mathbf{J}$ Fish Aquac [Internet]. 2010;2(3):87-92. Available from: http://www.academicjournals.org/IJFA

[9] Anggraini N, Adawiah SW, Ginting DNB, ... Analisis Spasial Kesesuaian Budidaya Kerapu Berbasis Data Penginderaan Jauh (Studi Kasus: Pulau Ambon Maluku). J Penginderaan ... [Internet]. 2019;16(2):113-22. Available from: http://103.16.223.27/index.php/jurnal_ inderaja/article/view/3180

[10] Radiarta IN, Saitoh SI, Miyazono A. GIS-based multi-criteria evaluation models for identifying suitable sites for Japanese scallop (Mizuhopecten yessoensis) aquaculture in Funka Bay, southwestern Hokkaido, Japan. Aquaculture [Internet]. 2008;284(1-
4):127-35. Available from: http://dx.doi.org/10.1016/j.aquaculture. 2008.07.048

[11] Palmer SCJ, Gernez PM, Thomas Y, Simis S, Miller PI, Glize P, et al. Remote Sensing-Driven Pacific Oyster (Crassostrea gigas) Growth Modeling to Inform Offshore Aquaculture Site Selection [Internet]. Vol. 6, Frontiers in Marine Science . 2020. p. 802. Available from: https://www.frontiersin.org/article/10.3 389/fmars.2019.00802

[12] Gorelick N, Hancher M, Dixon M, Ilyushchenko S, Thau D, Moore R. Google Earth Engine: Planetary-scale geospatial analysis for everyone. Remote Sens Environ [Internet]. 2017 Dec 1 [cited 2020 Apr 25];202:18-27. Available from: https://www.sciencedirect.com/science /article/pii/S0034425717302900

[13] KKP. Statistik Produksi Perikanan [Internet]. 2021. Available from: https://statistik.kkp.go.id/home.php?m $=$ total\& $\mathrm{i}=2$ \#panel-footer

[14] U.S. Geological Survey. Landsat 8 Data Users Handbook. Nasa [Internet]. 2016;8(June):97. Available from: https://landsat.usgs.gov/documents/La ndsat8DataUsersHandbook.pdf

[15] Nuriya H, Hidayah Z, Nugraha WA. Pengukuran konsentrasi klorofil-a dengan pengolahan Citra Landsat ETM-7 dan uji laboratorium di perairan selat Madura Bagian Barat. J Kelaut. 2010;3(1):60-5.

[16] Cahyono AB, Saptarini D, Pribadi CB, Armono HD. Estimation of Sea Surface Temperature (SST) Using Split Window Methods for Monitoring Industrial Activity in Coastal Area. Appl Mech Mater. 2017;862(February):90-5.

[17] Budhiman S, Hobma TW, Vekerdy Z. Remote sensing for Mapping TSM concentration in Mahakam Delta: an analytical approach. 13th Omi Work Valid Appl Satell Data Mar Resour Conserv. 2004;(January):5-1-5-14.

[18] Amante C, Eakins BW. ETOPO1 1 
Arc-Minute Global Relief Model: Procedures, Data Sources and Analysis. NOAA Tech Memo NESDIS NGDC$24 \quad$ [Internet]. 2009;(March): 19. Available from: http://www.ngdc.noaa.gov/mgg/global/ global.html

[19] Sidhu N, Pebesma E, Câmara G. Using Google Earth Engine to detect land cover change: Singapore as a use case. Eur J Remote Sens [Internet]. 2018;51(1):486-500. Available from: https://doi.org/10.1080/22797254.2018 .1451782

[20] Rijal SS. Mengolah Citra Pengindraan Jauh dengan Google Earth Engine [Internet]. 1st ed. Yogyakarta: Deepublish; 2020. 94 p. Available from:

https://books.google.co.id/books?id=W $\mathrm{JXwDwAAQBAJ} \& \operatorname{lpg}=\mathrm{PP} 1 \&$ ots $=\mathrm{quR}$ OlBWb22\&lr\&hl=id\&pg $=\mathrm{PP} 1 \# \mathrm{v}=$ one page $\& \mathrm{q} \& \mathrm{f}=$ false

[21] Eny D, Setyono D, Kangkan AL, Dan D, Kerang K, Anadara D, et al. Studi Penentuan Lokasi Pengembangan Budidaya Laut Berdasarkan Parameter Fisika, Kimia dan Biologi di Teluk Kupang, Nusa Tenggara Timur. Progr Pascasarj Univ Diponegoro [Internet]. 2006;2(1):1-9. Available from: http://eprints.undip.ac.id/15145/1/A_L eonidas_Kangkan.pdf\%0Ahttp://facult y.montgomerycollege.edu/gyouth/FP_ examples/student_examples/ishita_nan da/Types.html\%0Ahttps://doi.org/10.1 080/09638288.2019.1595750\%0Ahttp s://doi.org/10.1080/17518423.2017.13
$68728 \% 0 \mathrm{~A}$

[22] Wicaksono P, Lazuardi W. Assessment of PlanetScope images for benthic habitat and seagrass species mapping in a complex optically shallow water environment. Int J Remote Sens [Internet]. 2018;39(17):5739-65. Available from: https://doi.org/10.1080/01431161.2018 .1506951

[23] Utara GS, Tahun UN. PERDA_NOMOR_4_TAHUN_2019_ opt. 2019;

[24] Aswin MR. Google Earth Engine untuk Pemodelan Kesesuaian Lokasi Budidaya Ikan Kerapu (GEE-015) [Internet]. 2020. Available from: https://spatialmate.com/earth-enginepemodelan-kesesuaian-lokasibudidaya-kerapu/

[25] Sukresno B, Jatisworo D, Hanintyo R. Validation of Sea Surface Temperature from GCOM-C Satellite Using iQuam Datasets and MUR-SST in Indonesian Waters. Indones J Geogr. 2021;53(1).

[26] Wirasatriya A. Pola Distribusi Klorofila dan Total Suspended Solid (TSS) di Teluk Toli Toli, Sulawesi. Pola Distrib Klorofil-a dan Total Suspended Solid di Teluk Toli Toli, Sulawesi. 2011;1(1):10-2.

[27] Foody GM. Harshness in image classification accuracy assessment. Int J Remote Sens [Internet]. 2008 Jun 10;29(11):3137-58. Available from: https://doi.org/10.1080/014311607014 42120 